
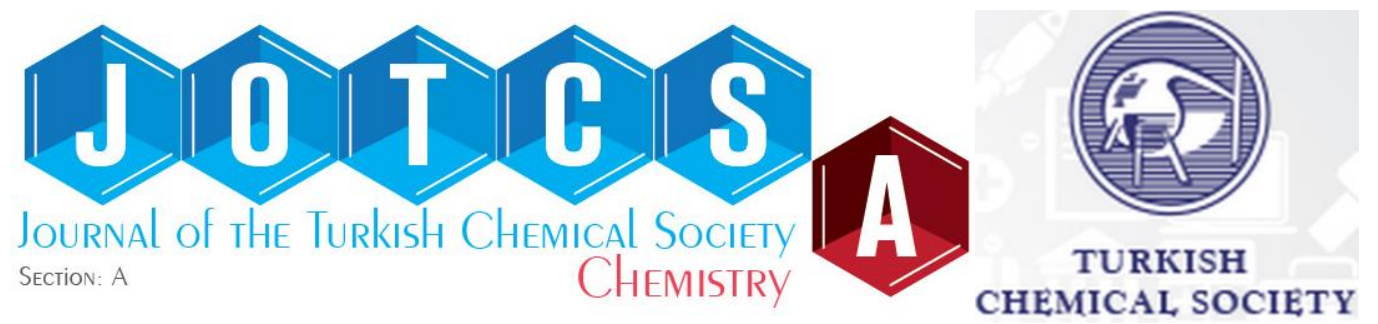

\title{
Design, synthesis and biological evaluation of 1,3-diaryltriazene- substituted sulfonamides as antioxidant, acetylcholinesterase and butyrylcholinesterase inhibitors
}

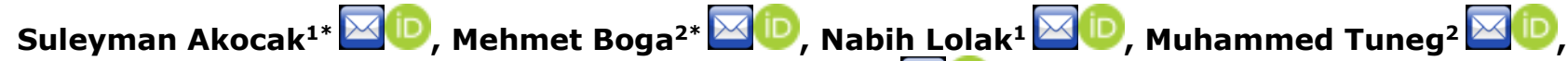 \\ Rajesh K.K. Sanku $\triangle$ (D), \\ ${ }^{1}$ Adiyaman University, Faculty of Pharmacy, Department of Pharmaceutical Chemistry, 02040, Adiyaman, \\ Turkey. \\ 2Dicle University, Faculty of Pharmacy, Department of Pharmaceutical Technology,21280, Diyarbakir, \\ Turkey. \\ 3University of Pennsylvania, Perelma School of Medicine, Department of Systems Pharmacology and \\ Translational Therapeutics, 19104, Philadelphia, United States
}

Abstract: 1,3-diaryltriazenes are one of the most useful and important linkers for many pharmaceutical applications. Therefore, in the current work, a series of 1,3-diaryltriazene sulfonamides 4 (a-k) were synthesized by reacting diazonium salt of sulfanylamide and substituted aromatic amine derivatives $\mathbf{3}$ (ak). The obtained compounds were investigated for antioxidant properties by using different methods such as a DPPH radical scavenging assay, ABTS radical decolarization, cupric reducing antioxidant capacity (CUPRAC) and metal chelating methods. The cholinesterase inhibition activities (acetylcholinesterase and butyrylcholinesterase) of synthesized compounds were also tested. In general, compounds showed weak antioxidant activity, except compounds $4 \mathbf{d}$ ( $\mathrm{IC}_{50}=114.89 \mu \mathrm{M}$ for DPPH activity), 4i $\left(\mathrm{IC}_{50}=25.31 \mu \mathrm{M}\right.$ for ABTS activity), $\mathbf{4 a}$ ( IC $_{50}=86.33 \mu \mathrm{M}$ for metal chelating activity), and $\mathbf{4 k}$ (absorbance value $1.229 \mu \mathrm{M}$ for CUPRAC). Some of the compounds showed great \% inhibition against both acetylcholinesterase and butyrylcholinesterase with $\%$ inhibition values ranging from 11.54 to 93.67 and 62.24 to 98.47 , respectively.

Keywords: Sulfanylamide, 1,3-diaryltriazene, antioxidant, anticholinesterase.

Submitted: January 22, 2019. Accepted: February 01, 2019.

Cite this: Akocak S, Boga M, Lolak N, Tuneg M, Sanku R. Design, synthesis and biological evaluation of 1,3-diaryltriazene-substituted sulfonamides as antioxidant, acetylcholinesterase and butyrylcholinesterase inhibitors. JOTCSA. 2019;6(1):63-70.

DOI: https://dx.doi.org/10.18596/jotcsa.516444.

*Corresponding authors. E-mail: akocaksuleyman@gmail.com, mehmetboga1980@gmail.com.

\section{INTRODUCTION}

Sulfur-containing drugs, especially sulfonamides, are used for various pharmaceutical applications. Their importance can be dated back from the first use of sulfonamide containing antibacterial drugs. Sulfonamides are used for a wide range of biological applications such as antibacterial (1-3), anti-inflammatory $(4,5)$, antioxidant (6-8), anticancer (9-14), carbonic anhydrase inhibitors (10, 15-17) and for Alzheimer's disease $(18,19)$. There are more than 112 FDA approved drugs containing sulfonamide group (20).
Alzheimer's disease (AD) is a neurodegenerative disorder featured with cognitive dysfunction and dementia (20). According to the present estimation, about 50 million people are going through this disease and this number might triple up to 152 million by 2050 (World Alzheimer report). Unfortunately, the medicines used for the cure of $A D$ and its progression are not discovered yet. There are some pathophysiology factors like beta-amyloid deposits, inflammation, oxidative stress, dyshomeostasis of biometals, tau-protein aggregation, deficiencies of acetylcholine (ACh) and butyrylcholine (BCh) which are believed to be responsible for the disease progression (21-23). 
Inhibition of $\mathrm{ACh}$ and $\mathrm{BCh}$ hydrolysis by using acetylcholinesterase (AChE) and butyrylcholinesterase (BChE) inhibitors has been considered to increase the level of the ACh and $\mathrm{BCh}$ in synapses aiding the restoration of the cholinergic neurotransmission and cognitive capabilities $(24,25)$. First-line drugs in the symptomatic treatment of $A D$ treatment involve the use of cholinesterase inhibitors such as rivastigmine, galantamine and donepezil (24), but these drugs are reported to have side effects like nausea, gastrointestinal upset, diarrhea, muscular weakness, syncope and weight loss (26). On the other hand, antioxidants are thought to offer a good possibility of combating neurodegeneration and protection against Alzheimer's disease $(27,28)$. Therefore, there is a need for less toxic cholinesterase inhibitors along with antioxidant properties for AD treatment.

More recently, our research group showed the efficient human carbonic anhydrase II (hCA II) inhibition profile of 1,3-diaryltriazene sulfonamides $(29,30)$. The nanomolar potency was obtained against one of the most abundant isoform hCA II. In the current study, we are focusing on the role of 1,3-diaryltriazene sulfonamides as antioxidant, acetylcholinesterase and butyrylcholinesterase inhibitors, prompted by the potent carbonic anhydrase inhibition results.

\section{EXPERIMENTAL SECTION}

\section{Chemistry}

General synthetic route for the preparation of 1,3-diaryltriazene-substituted sulfonamides 4(ak) are depicted in Figure 1 . The synthesis of the compounds was done as previously described by us $(29,30)$. Briefly, a solution of sulfanylamide $\mathbf{1}$ (5 mmol) in $\sim 1-1.5 \mathrm{ml}$ of conc. hydrochloric acid and $5 \mathrm{ml}$ of water was cooled to $0-5{ }^{\circ} \mathrm{C}$. Then, sodium nitrite $(7 \mathrm{mmol})$ in $5 \mathrm{~mL}$ of water was added dropwise to the solution under continuous stirring. The mixture was stirred about 15-20 min at $0-5{ }^{\circ} \mathrm{C}$, and diazonium solution was added to aromatic amines (prepared by $5 \mathrm{mmol}$ anilines in $5 \mathrm{~mL}$ of $\mathrm{MeOH}$ ) by adjusting the $\mathrm{pH}$ around 6-7 with a saturated sodium acetate solution. After that, the reaction mixture was stirred 5-6 h at 0$5{ }^{\circ} \mathrm{C}$ and overnight at room temperature in dark. The obtained colorful mixture was filtered off, washed several times with cold water, and then crystallized from ethanol. Physicochemical and spectroscopic characterization of all compounds 4(a-k) have been previously described by us (29).

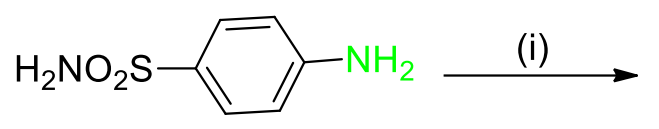

1

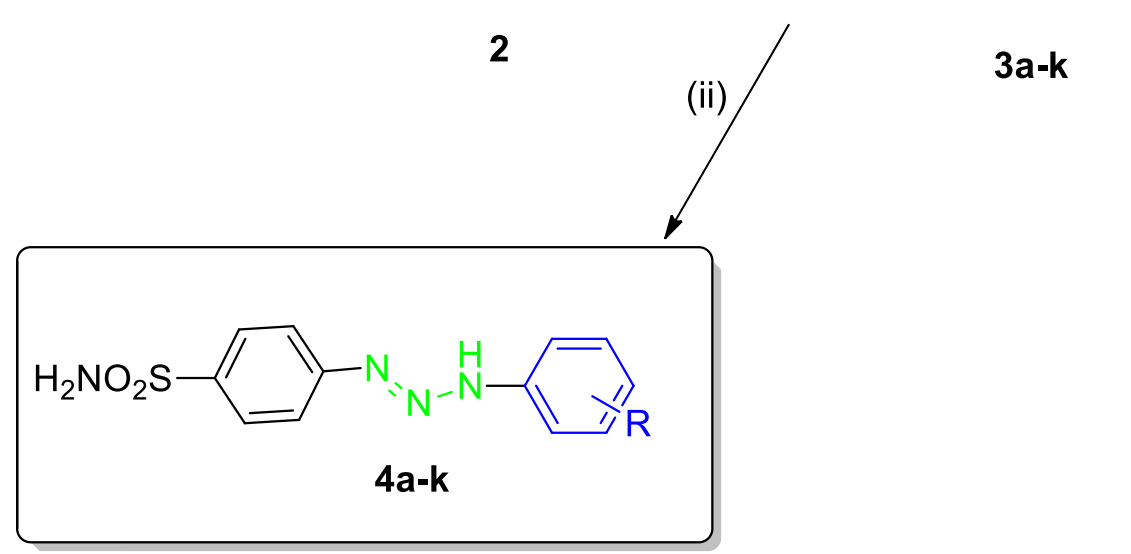

Figure 1. General synthetic route for the synthesis of 1,3-diaryltriazene sulfonamides $\mathbf{4 a - k}$.

\section{DPPH Free radical scavenging assay}

The DPPH (2,2-diphenyl-1-picrylhydrazyl) radical scavenging activity of the synthesized compounds was determined by spectrophotometric method based on the reduction of a ethanolic solution of DPPH (31). 2 , $5,10,20 \mu \mathrm{L}$ of $1 \mathrm{mM}$ stock solution of each compound were completed to $40 \mu \mathrm{L}$ with DMSO and mixed with $160 \mu \mathrm{L}$ of $0.1 \mathrm{mM}$ of DPPH free radical solution. The mixture was left to stand for $30 \mathrm{~min}$ in the dark and the absorbance was then measured at $517 \mathrm{~nm}$ against a blank. Inhibition of free radical, DPPH, in percent (I\%) was calculated according to the formula:

$$
\begin{gathered}
\text { I } \%=\left(A_{\text {control }}-A_{\text {sample }}\right) / A_{\text {control }} \times \\
100 ;
\end{gathered}
$$

where $A_{\text {control }}$ is the absorbance of the control reaction (containing all reagents except for the tested compounds), and $A_{\text {sample }}$ is the absorbance of the test compounds. Tests were carried out in triplicate. BHA (butylated hydroxyanisole), BHT (butylated hydroxytoluene) and a-Toc (aTocopherol) were used as positive control.

\section{ABTS cation radical scavenging assay}

$$
\text { The ABTS }{ }^{+} \text {(2,2 -azino-bis(3- }
$$
ethylbenzothiazoline-6-sulfonic acid)), cationic radical scavenging activity assay determines the inhibition percentage as a function of time and concentration, and evaluated relative to the activity of BHT, BHA and a-Toc (32). 2, 5, 10 and $20 \mu \mathrm{L}$ of $1 \mathrm{mM}$ stock solutions were completed to $40 \mu \mathrm{L}$ with the DMSO. Then $160 \mu \mathrm{L}$ of $7 \mathrm{mM} \mathrm{ABTS}$ 
solutions were added into each well in the micro plate. After keeping them for 6 min in dark at room temperature, the absorbances were measured at $734 \mathrm{~nm}$. ABTS cation radical scavenging activities as \% inhibition were determined by using the below equation:

$$
\begin{gathered}
\% \text { Inhibition }=\left(A_{\text {control }}{ }^{-}\right. \\
\left.A_{\text {sample }}\right) / A_{\text {control }} \times 100
\end{gathered}
$$

where $A$ is the absorbance. Tests were carried out in triplicate. BHA, BHT and a-Toc were used as positive control.

\section{Metal Chelating Activity}

The chelating ability of synthesized compounds was examined according to the method of Dinis et al. (33). 2, 5, 10 and $20 \mu \mathrm{L}$ of $1 \mathrm{mM}$ stock solutions were completed to $188 \mu \mathrm{L}$ with the DMSO. Then, each sample was mixed with $4 \mu \mathrm{L}$ of $2 \mathrm{mM}$ iron(II) chloride. The reaction was started by adding $8 \mu \mathrm{L}$ of $5 \mathrm{mM}$ ferrozine. The mixture was left to stand for $10 \mathrm{~min}$ at room temperature, then the absorbance was measured at $562 \mathrm{~nm}$ against a blank. The results were expressed as percentage of inhibition of the ferrozine $-\mathrm{Fe}^{2+}$ complex formation. EDTA was used as a positive control. The percentage inhibition of the ferrozine $-\mathrm{Fe}^{2+}$ complex formation was calculated using the formula given below:

$$
\begin{gathered}
\text { Chelating ability }(\%)=\left(A_{\text {control }}{ }^{-}\right. \\
\left.A_{\text {sample }}\right) / A_{\text {control }} \times 100
\end{gathered}
$$

\section{Cupric reducing antioxidant capacity (CUPRAC) assay}

CUPRAC method comprises the reduction of $\mathrm{Cu}(\mathrm{II})$-Neocuproine into its colored form $\mathrm{Cu}(\mathrm{I})$ Neocuproine chelate in the presence of antioxidant compounds (34). The absorbance at $450 \mathrm{~nm}$ was measured when the complex was obtained. $61 \mu \mathrm{L}$ of $10 \mathrm{mM} \mathrm{CuCl} 2,61 \mu \mathrm{L}$ of $7.5 \mathrm{mM}$ Neocuproine and $61 \mu \mathrm{L}$ of $1 \mathrm{M}$ of $\mathrm{NH}_{4} \mathrm{OAc}$ solutions were added into the prepared solutions to adjust the concentrations as $10,25,50$, and $100 \mu \mathrm{M}$. The absorbance values were compared with the standard molecules BHA, BHT and a-Toc. Each of samples was applied three times to verify the results.

\section{Anticholinesterase inhibition assay}

The inhibitory effect of 1,3-diaryltriazenesubstituted sulfonamide derivatives $\mathbf{4}(\mathbf{a}-\mathbf{k})$ on AChE and BChE activities was determined according to the slightly modified spectrophotometric method of Ellman et al. (35). All compounds were dissolved in DMSO to prepare stock solutions at $4 \mathrm{mM}$ concentration. Aliquots of $150 \mu \mathrm{L}$ of $100 \mathrm{mM}$ sodium phosphate buffer $(\mathrm{pH}$ 8.0), $10 \mu \mathrm{L}$ of sample solution and $20 \mu \mathrm{L}$ AChE (or $\mathrm{BChE}$ ) solution were mixed and incubated for 15 $\min$ at $25{ }^{\circ} \mathrm{C}$, and DTNB (5,5'-dithio-bis(2nitrobenzoic acid)) (10 $\mu \mathrm{L})$ is added. The reaction was then initiated by the addition of acetylthiocholine iodide (or butyrylthiocholine

The results revealed that some of the compounds from the series show good ABTS cation radical scanvenging activity. The compound 4i $(3,4-$ diMeO) showed the best ABTS activity with IC $_{50}$ value of $25.31 \mu \mathrm{M}$, which is more active than the iodide) (10 $\mu \mathrm{L}) .30$ minutes after addition of substrates (acetylthiocholine iodide or butyrylthiocholine iodide), the absorbances were measured at $412 \mathrm{~nm}$. The final concentration of the tested compounds' solution was $200 \mu \mathrm{M}$.

$\%$ Inhibition $=\left(A_{\text {control }}-A_{\text {sample }}\right) / A_{\text {control }} \times 100$ where $A$ is the absorbance. Tests were carried out in triplicate. Galantamine was used as positive control.

\section{Statistical analysis}

The results of the antioxidant and anticholinesterase activity assays are expressed as the mean \pm SD of three parallel measurements. The statistical significance was estimated using a Student's t-test, where pvalues $<0.05$ were considered significant.

\section{RESULTS AND DISCUSSION}

In the present study, we report the synthesis, antioxidant, acetylcholinesterase and butyrylcholinesterase inhibition activities of 1,3diaryltriazene-substituted sulfonamide derivatives $\mathbf{4}(\mathbf{a}-\mathbf{k})$ obtained from sulfanylamide as a lead molecule. The compounds were obtained via the reaction of diazonium salt of sulfanylamide with substituted aromatic amine derivatives $\mathbf{3}(\mathbf{a}-\mathbf{k})$. These compounds were previously synthesized and fully characterized by us a potent and selective human carbonic anhydrase II (hCA II) inhibitors.

The antioxidant capacities of prepared 1,3diaryltriazene-substituted sulfonamides are assayed by using several antioxidant methods, including DPPH free radical scanvenging, ABTS cation radical scavenging, cupric reducing (CUPRAC) and metal chelating methods. Also, acetylcholinesterase (AChE) and butyrylcholinesterase (BChE) inhibitory activities were investigated.

The DPPH free radical scavenging activity of the synthesized compounds was assayed and compared with BHT, BHA and a-TOC used as standards. The DPPH free radical scavenging activity of the synthesized compounds is given in Table 1 as an $\mathrm{IC}_{50}$ values. As depicted in Table 1 , three compounds show better DPPH activity than the standard $\mathrm{BHT}$, which are $4 \mathbf{d}(4-\mathrm{CN})$, 4f (4$\mathrm{BuO})$ and $\mathbf{4 j}(2,3,4,5,6-\mathrm{F})$ with $\mathrm{IC}_{50}$ values of $114.89,162.29$, and $219.88 \mu \mathrm{M}$, respectively. In case of compounds $4 \mathbf{a}(4-\mathrm{F}), \mathbf{4 b}(4-\mathrm{Cl}), 4 \mathbf{c}$ (4$\mathrm{MeO}), \mathbf{4 e}(4-\mathrm{Acetyl}), \mathbf{4 g}(2-\mathrm{CN}), \mathbf{4 h}\left(3-\mathrm{NO}_{2}\right)$, and 4i $(3,4-d i M e O)$, there was no significant $\mathrm{DPPH}$ activity with $\mathrm{IC}_{50}$ values of $>1000 \mu \mathrm{M}$. On the other hand, all compounds displayed lesser DPPH activity than other standards BHA and a-TOC.

standards BHA, BHT and a-TOC. The compounds $4 f$ (4-BuO) and $4 \mathbf{j}(2,3,4,5,6-F)$ were also sensitive to ABTS cation radical scavenging activity with $\mathrm{IC}_{50}$ values of 53.01 and $50.79 \mu \mathrm{M}$, respectively. The $\mathrm{IC}_{50}$ values of the remaining 
compounds were ranging from 108.89 to 610.34 $\mu \mathrm{M}$, except the compound $4 \mathbf{d}$ (4-CN) which has no ABTS cation radical scavenging activity ( IC $_{50}$ $>1000 \mu \mathrm{M}$ ) as demonstrated in Table 1.

The metal chelating properties of the 1,3diaryltriazene-substituted sulfonamide derivatives $\mathbf{4 ( a - k )}$ on iron(II) ions were presented in Table 1 and compared with standard EDTA. It was considered that compound 4a (4-F) and 4e (4-acetyl) were the most active compounds with $\mathrm{IC}_{50}$ values 86.33 and $99.10 \mu \mathrm{M}$, respectively, which showed chelating activity similar to standard compound EDTA ( IC $_{50}=52.35$ $\mu \mathrm{M})$. Also, compounds 4c (4-MeO), 4d (4-CN), $\mathbf{4 g}(2-\mathrm{CN})$ and $\mathbf{4 h}\left(3-\mathrm{NO}_{2}\right)$ showed moderate activity with IC $_{50}$ values ranging from 120.52 to $198.86 \mu \mathrm{M}$. The remaining compounds had no activity in metal chelating assay with $\mathrm{IC}_{50}$ values $>1000 \mu \mathrm{M}$ (Table 1).

Table 1. DPPH free radical scavenging, ABTS cation radical scavenging and metal chelating activities of 1,3-diaryltriazene-substituted sulfonamides $\mathbf{4 ( a - k )}$ and controls BHA, BHT, a-Toc, and EDTA.

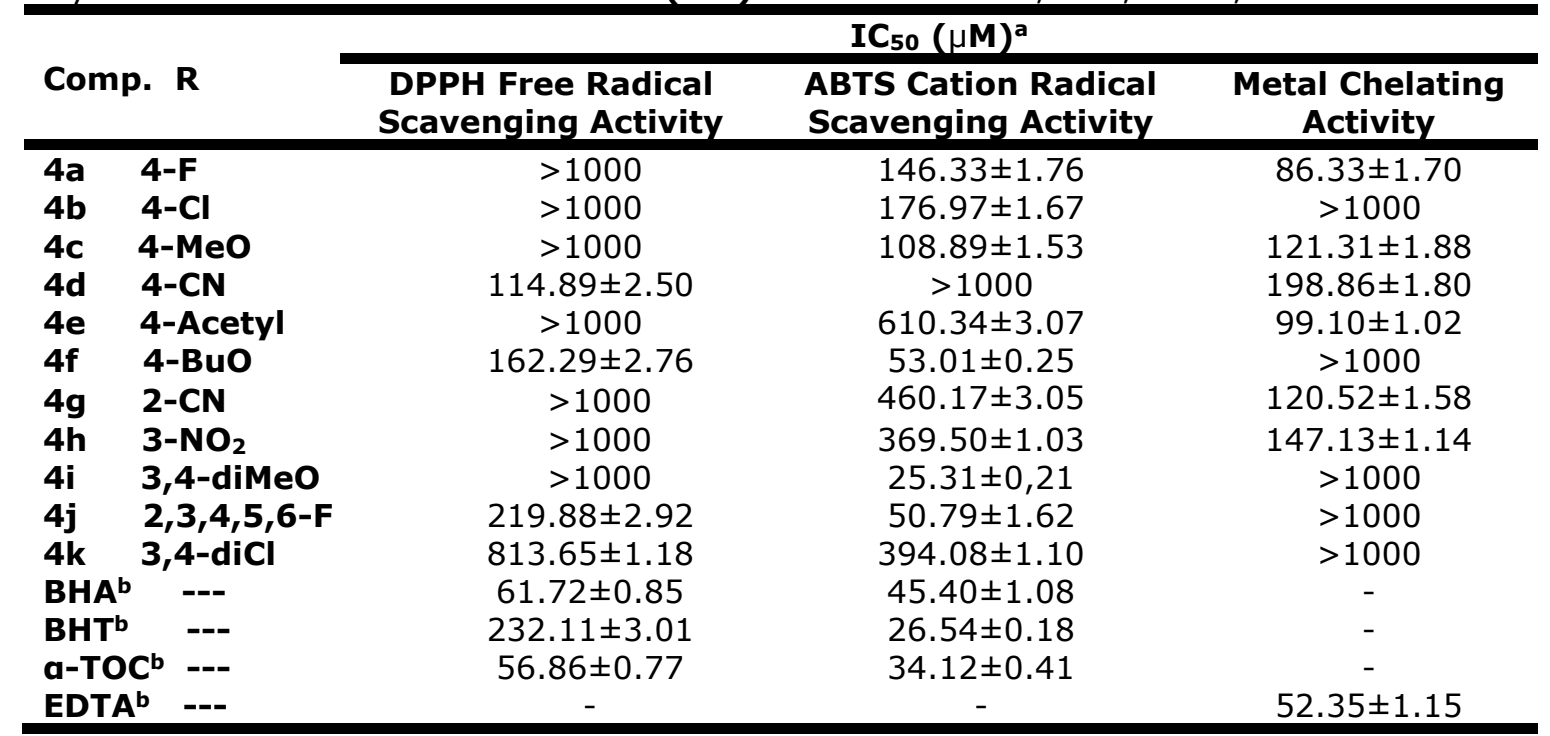

${ }^{a} \mathrm{IC}_{50}$ values represent the means (standard deviation of three parallel measurements) $(p<0.05)$.

b Reference compounds.

Table 2. Cupric ion reducing antioxidant capacity (CUPRAC) of the 1,3-diaryltriazene-substituted sulfonamides 4(a-k) and controls BHA, BHT, and a-Toc.

\begin{tabular}{|c|c|c|c|c|c|}
\hline \multirow{2}{*}{\multicolumn{2}{|c|}{ Comp. R }} & \multicolumn{4}{|c|}{ Absorbance Values $(\mu M)^{a}$} \\
\hline & & \multirow{2}{*}{$\begin{array}{c}\mathbf{1 0} \boldsymbol{\mu M} \\
0.102 \pm 0.013\end{array}$} & \multirow{2}{*}{$\begin{array}{c}\mathbf{2 5} \boldsymbol{\mu} \mathbf{M} \\
0.119 \pm 0.002\end{array}$} & \multirow{2}{*}{$\begin{array}{c}\mathbf{5 0} \boldsymbol{\mu M} \\
0.155 \pm 0.008\end{array}$} & \multirow{2}{*}{$\frac{\mathbf{1 0 0} \boldsymbol{\mu M}}{0.168 \pm 0.006}$} \\
\hline & 4-F & & & & \\
\hline & 4-Cl & $0.079 \pm 0.004$ & $0.111 \pm 0.036$ & $0.127 \pm 0.021$ & $0.168 \pm 0.009$ \\
\hline & 4-MeO & $0.271 \pm 0.088$ & $0.224 \pm 0.008$ & $0.418 \pm 0.058$ & $0.744 \pm 0.051$ \\
\hline & 4-CN & $0.095 \pm 0.003$ & $0.099 \pm 0.005$ & $0.188 \pm 0.062$ & $0.244 \pm 0.043$ \\
\hline & 4-Acetyl & $0.340 \pm 0.001$ & $0.406 \pm 0.001$ & $0.549 \pm 0.004$ & $0.889 \pm 0.008$ \\
\hline & 4-BuO & $0.166 \pm 0.064$ & $0.236 \pm 0.036$ & $0.366 \pm 0.044$ & $0.882 \pm 0.046$ \\
\hline & $2-\mathrm{CN}$ & $0.102 \pm 0.004$ & $0.098 \pm 0.012$ & $0.134 \pm 0.002$ & $0.151 \pm 0.001$ \\
\hline & $3-\mathrm{NO}_{2}$ & $0.131 \pm 0.057$ & $0.127 \pm 0.036$ & $0.250 \pm 0.083$ & $0.301 \pm 0.019$ \\
\hline & 3,4-diMeO & $0.176 \pm 0.006$ & $0.328 \pm 0.004$ & $0.626 \pm 0.016$ & $1.083 \pm 0.022$ \\
\hline & $2,3,4,5,6-F$ & $0.122 \pm 0.006$ & $0.156 \pm 0.005$ & $0.197 \pm 0.008$ & $0.290 \pm 0.024$ \\
\hline & 3,4-diCl & $0.599 \pm 0.001$ & $0.726 \pm 0.008$ & $0.965 \pm 0005$ & $1.229 \pm 0.002$ \\
\hline \multicolumn{2}{|c|}{$\mathbf{B H A}^{\mathrm{b}}$} & $0.288 \pm 0.015$ & $0.572 \pm 0.046$ & $1.026 \pm 0.013$ & $1.984 \pm 0.035$ \\
\hline \multicolumn{2}{|c|}{ BHT' } & $0.303 \pm 0.010$ & $0.610 \pm 0.010$ & $1.167 \pm 0.024$ & $2.000 \pm 0.173$ \\
\hline \multicolumn{2}{|c|}{$a-T O C^{b}$} & $0.179 \pm 0.001$ & $0.296 \pm 0.012$ & $0.482 \pm 0.017$ & $0.912 \pm 0.065$ \\
\hline
\end{tabular}

avalues expressed are means \pm SD of three parallel absorbance measurements $(p<0.05){ }^{b}$ Reference compounds

The cupric reducing antioxidant capacity (CUPRAC) method was also applied to identify the antioxidant capacity of the prepared 1,3diaryltriazene-substituted sulfonamide derivatives. As expected, the activity of the compounds increased with increasing concentration as summarized in Table 2 . The compounds 4i (3,4-diMeO) and $4 \mathbf{k}(3,4-\mathrm{diCl})$ showed a better CUPRAC capacity than standard a-TOC. The compound $\mathbf{4 k}$ had better activity at concentrations 10 and $25 \mu \mathrm{M}$ than all three standards. Interestingly, these two active 
compounds have 3,4-disubstitution on the phenyl ring make them different from the rest of the compounds.

Table 3. Anticholinesterase activities of the 1,3-diaryltriazene-substituted sulfonamides $\mathbf{4 ( a - k )}$ at 200 $\mu \mathrm{M}$ and standard drug galanthamine.

\begin{tabular}{|c|c|c|c|}
\hline Comp. & $\mathbf{R}$ & AChE (Inhibition \%) & BChE (Inhibition \%)a \\
\hline $\begin{array}{l}\text { 4a } \\
4 b \\
4 c \\
4 d \\
4 e \\
4 f \\
4 g \\
4 h \\
4 i \\
4 j \\
4 k \\
\text { Galanta }\end{array}$ & $\begin{array}{l}\text { 4-F } \\
4-\mathrm{Cl} \\
4-\mathrm{MeO} \\
4-\mathrm{CN} \\
4-\mathrm{Acetyl} \\
4-\mathrm{BuO} \\
2-\mathrm{CN} \\
3-\mathrm{NO}_{2} \\
\text { 3,4-diMeO } \\
\text { 2,3,4,5,6-F } \\
\text { 3,4-diCl } \\
\text { Imine }^{\text {b }}\end{array}$ & $\begin{array}{l}11.54 \pm 0.26 \\
13.55 \pm 0.76 \\
25.16 \pm 0.64 \\
33.50 \pm 0.49 \\
84.48 \pm 1.02 \\
67.07 \pm 0.48 \\
69.60 \pm 0.67 \\
67.70 \pm 0.27 \\
85.01 \pm 0.78 \\
93.67 \pm 0.30 \\
55.35 \pm 0.32 \\
84.20 \pm 0.74\end{array}$ & $\begin{array}{l}84.18 \pm 1.20 \\
67.26 \pm 1.39 \\
90.22 \pm 0.88 \\
79.00 \pm 0.46 \\
77.21 \pm 0.20 \\
82.14 \pm 4.33 \\
62.24 \pm 1.16 \\
71.51 \pm 1.80 \\
90.22 \pm 0.10 \\
98.47 \pm 0.56 \\
97.00 \pm 0.61 \\
87.86 \pm 0.24\end{array}$ \\
\hline
\end{tabular}

a $200 \mu \mathrm{M}$, b Standard drug

In the current series of 1,3-diaryltriazene sulfonamides, most of the compounds showed great potency against both cholinesterase enzymes (AChE and BChE). In general, all compounds had higher BChE inhibition activity than AChE inhibition activity, except the compounds $\mathbf{4 e}$ (4-acetyl) and $\mathbf{4 g}(4-\mathrm{CN})$. In case of AChE inhibition, the compounds $\mathbf{4 e}, \mathbf{4 i}$ and $\mathbf{4 j}$ showed better activity than standard drug galanthamine with \%inhibition values of 84.48 , 85.01 and 93.67 , respectively. The compounds $\mathbf{4 f}$ (4-BuO), $\mathbf{4 g}(2-\mathrm{CN}), \mathbf{4 h}\left(3-\mathrm{NO}_{2}\right)$ and $\mathbf{4 k}(3,4-$ $\mathrm{diCl})$ were moderate inhibitors of this enzyme with \%inhibition values ranging from 55.35 to 69.60. For BChE activity, compounds $\mathbf{4 j}$ $(2,3,4,5,6-\mathrm{F})$ and $4 \mathbf{k}(3,4-\mathrm{diCl})$ showed the highest \%inhibition at $200 \mu \mathrm{M}$ with 98.47 and 97.00 , respectively. The remaining compounds also showed good inhibition against BChE enzyme with \%inhibition values ranging from 62.24 to 90.22.

\section{CONCLUSIONS}

In the present study, 1,3-diaryltriazene sulfonamides $\mathbf{4}(\mathbf{a}-\mathbf{k})$ were synthesized from the reaction of diazonium salt of sulfonamide and substituted aromatic amines. The antioxidant activities of the compounds were investigated by DPPH, ABTS, metal chelating and CUPRAC methods. The AChE and BChE inhibition studies were also examined. In general, compounds showed weak DPPH, ABTS, metal chelating and CUPRAC activity. However, several compounds were good and promising antioxidant capacity, such as compounds $4 \mathbf{d}$ ( $\mathrm{IC}_{50}=114.89 \mu \mathrm{M}$ for DPPH activity), 4i $\left(\mathrm{IC}_{50}=25.31 \mu \mathrm{M}\right.$ for $\mathrm{ABTS}$ activity), $4 \mathrm{a}$ ( IC $_{50}=86.33 \mu \mathrm{M}$ for metal chelating activity), and 4k (absorbance value $1.229 \mu \mathrm{M}$ for CUPRAC). The best biological results were obtained against BChE enzyme inhibition in this study. Specifically, compounds $\mathbf{4 j}$ and $\mathbf{4 k}$ showed excellent \%inhibition against this enzyme with \%inhibition values of 98.47 and 97.00, respectively. Since the AChE and BChE enzymes are related with neurodegenerative disorders and their inhibition is important for this type of brain disorders, these 1,3-diaryltriazene sulfonamides may be considered of interest for in vivo studies.

\section{ACKNOWLEDGMENTS}

This work was partially funded by The Scientific and Technological Research Council of Turkey (TUBITAK) with Grant no. 216 S907.

\section{REFERENCES}

1. Konda $\mathrm{S}$, Srujana $\mathrm{R}$, Bhaskar $\mathrm{K}$, Munaganti RK, Gugloth V, Nagarapu L, Akkewar DM. Synthesis and antimicrobial activity of novel benzoxazine sulfonamide derivatives. Bioorg Med Chem Lett. $2015 ; 25(7): 1643-6$.

2. Durgun $M$, Turkmen $H$, Zengin $G$, Zengin $H$, Koyunsever M, Koyuncu I. Synthesis, characterization, in vitro cytotoxicity and antimicrobial investigation and evaluation of physicochemical properties of novel 4(2-

methylacetamide)benzenesulfonamide derivatives. Bioorg Chem. 2017;70:16372.

3. Genc $Y$, Ozkanca $R$, Bekdemir $Y$. Antimicrobial activity of some sulfonamide derivatives on clinical isolates of Staphylococus aureus. Ann Clin Microbiol Antimicrob. 2008 Aug;(7):17-23.

4. Chandna N, Kumar S, Kaushik P, Kaushik D, Roy SK, Gupta GK, Jachak SM, Kapoor JK, Sharma PK. Synthesis of novel celecoxib analogues by bioisosteric 
replacement of sulfonamide as potent anti-inflammatory agents and cyclooxygenase inhibitors. Bioorg Med Chem. 2013;21(15):4581-90.

5. Bano S, Javed K, Ahmad S, Rathish IG, Singh S, Alam MS. Synthesis and biological evaluation of some new 2pyrazolines bearing benzene sulfonamide moiety as potential anti-inflammatory and anti-cancer agents. Eur J Med Chem. 2011;46(12):5763-8.

6. Gocer $\mathrm{H}$, Akincioglu A, Oztaskin N, Goksu S, Gulcin I. Synthesis, antioxidant, and antiacetylcholinesterase activities of sulfonamide derivatives of dopaminerelated compounds. Arch Pharm. 2013 Oct;346(11):783-92.

7. Ning $X$, Guo $Y$, Ma $X$, Zhu $R$, Tian $C$, Zhang $Z$, Wang $X, M a ~ Z$, Liu J. Design, synthesis and pharmacological evaluation of (E)-3,4-dihydroxy styryl sulfonamides derivatives as multifunctional neuroprotective agents against oxidative and inflammatory injury. Bioorg Med Chem. 2013;21(17):5589-97.

8. Garibov E, Taslimi P, Sujayev A, Bingol Z, Cetinkaya S, Gulcin I, Beydemir S, Farzaliyev V, Alwasel SH, Supuran CT. Synthesis of 4,5-disubstituted-2-thioxo1,2,3,4-tetrahydropyrimidines and investigation of their acetylcholinesterase, butyrylcholinesterase, carbonic anhydrase I/II inhibitory and antioxidant activities. J Enzyme Inhib Med Chem. 2016;31:1-9.

9. Lu XY, Wang ZC, Ren SZ, Shen FQ, Man RJ, Zhu HL. Coumarin sulfonamides derivatives as potent and selective COX2 inhibitors with efficacy in suppressing cancer proliferation and metastasis. Bioorg Med Chem Lett. 2016;26(15):3491-8.

10. Akocak S, Alam MR, Shabana AM, Sanku RKK, Vullo D, Thompson H, Swenson ER, Supuran CT, Ilies MA. PEGylated Bissulfonamide carbonic anhydrase inhibitors can efficiently control the growth of several carbonic anhydrase IXexpressing carcinomas. J Med Chem 2016;59(10):5077-88.

11. Lolak N, Akocak S, Bua S, Supuran CT. Design, synthesis and biological evaluation of novel ureido benzenesulfonamides incorporating 1,3,5-triazine moieties as potent carbonic anhydrase IX inhibitors. Bioorg Chem. 2019;82:117-22.
12. Casini A, Scozzafava A, Mastrolorenzo A, Supuran CT. Sulfonamides and sulfonylated derivatives as anticancer agents. Curr Cancer Drug Targetd. $2002 ; 2(1): 55-75$.

13. Canakci D, Koyuncu I, Lolak N, Durgun M, Akocak S, Supuran CT. Synthesis and cytotoxic activities of novel copper and silver complexes of 1,3-diaryltriazenesubstituted sulfonamides. J Enzyme Inh Med Chem. 2019;34(1):110-6.

14. Zhao C, Rakesh KP, Ravidar L, Fang WY, Qin HL. Pharmaceutical and medicinal significance of sulfur $\left(\mathrm{S}^{\mathrm{VI}}\right)$-containing motifs for drug discovery: A critical review. Eur J Med Chem. 2019;162:679734.

15. Akocak S, Lolak N, Nocentini A, Karakoc G, Tufan A, Supuran CT. Synthesis and biological evaluation of novel aromatic and heterocyclic bis-sulfonamide Schiff bases as carbonic anhydrase I, II, VII and IX inhibitors. Bioorg Med Chem. 2017;25(12):3093-7.

16. Akocak S, Lolak N, Bua S, Turel I, Supuran CT. Synthesis and biological evaluation of novel N,N'-diaryl cyanoguanidines acting as potent and selective carbonic anhydrase II inhibitors. Bioorg Chem. 2018;77:245-1.

17. El-Gazzar MG, Nafie NH, Nocentini A, Ghorab MM, Heiba HI, Supuran CT. Carbonic anhydrase inhibition with a series of novel benzenesulfonamidetriazole conjugates. J Enzyme Inhib Med Chem. 2018;33(1):1565-74.

18. Bag $S$, Tulsan $R$, Sood $A$, Cho $H$, Redjeb $H$, Zhou W, LeVine $H$, Torok B, Torok $M$. Sulfonamides as multifunctional agents for Alzheimer's disease. Bioorg Med Chem Lett. $2015 ; 25(3)$ :626-30.

19. Rishton GM, Retz DM, Tempest PA, Novontny J, Kahn S, Treanor JJ, Lile JD, Ciltron M. Fencyhylamine sulfonamide inhibitors of amyloid beta peptide production by the gamma-secretase proteolytic pathway: potential smallmolecule therapeutic agents for the treatment of Alzheimer's disease. J Med Chem. 2000;43(12):2297-9.

20. Wang J, Gu BJ, Masters CL, Wang YJ. A systemic view of Alzheimer diseaseinsights from amyloid- $\beta$ metabolism beyond the brain. Nat Rev Neurol. 2017;13(10):612-23. 
21. Swerdlow RH. Pathogenesis of Alzheimer's disease. Clin Interv Aging. 2007;2(3):347-59.

22. Dong S, Duan $Y$, Hu Y, Zhao Z. Advances in the pathogenesis of Alzheimer's disease: a re-evaluation of amyloid cascade hypothesis. Transl Neurodegener. 2012;1(1):1-18.

23. Greig $\mathrm{NH}$, Lahiri DK, Sambamurti K. Butyrylcholinesterase: an important new target in Alzheimer's disease therapy. Int Psychogeriatr. 2002; 14:77-91.

24. Gulcin I, Scozzafav A, Supuran CT, Akincioglu H, Koksal Z, Turkan F, Alwasel $S$. The effect of caffeic acid phenethyl ester (CAPE) on metabolic enzymes including acetylcholinesterase, butyrylcholinesterase, glutathione Stransferase, lactoperoxidase, and carbonic anhydrase isozymes I, II, IX, and XII. J Enzyme Inhib Med Chem. 2016;31(6): 1095-101.

25. Oztaskin N, Cetinkaya Y, Taslimi P. Goksu S, Gulcin I. Antioxidant and acetylcholinesterase inhibition properties of novel bromophenol derivatives. Bioorg Chem. 2015;60:49-57.

26. Casey DA, Antimisiaris D, O'Brien J. Drugs for Alzheimer's disease: are they effective?. P T. 2010;35(4):208-11.

27. Klatte ET, Scharre DW, Nagaraja HN, Davis RA, Reversdorf DQ. Combination therapy of donepezil and vitamin $E$ in Alzheimer disease. Alzheimer Dis Assoc Disord. 2003;17(2):113-6.

28. Cai $P$, Fang $S Q$, Yang $H L$, Yang $X L$, Liu $\mathrm{QH}$, Kong LY, Wang XB. Donepezilbutylated hydroxytoluene (BHT) hybrids as Anti-Alzheimer's disease agents with cholinergic, antioxidant, and neuroprotective properties. Eur J Med Chem. 2018;5(157):161-76.

29. Lolak N, Akocak S, Bua S, Koca M, Supuran CT. Design and synthesis of novel 1,3-diaryltriazene-substituted sulfonamides as potent and selective carbonic anhydrase II inhibitors. Bioorg Chem. 2018;77:542-7.

30. Akocak S, Lolak N, Bua S, Supuran CT. Discovery of novel 1,3-diaryltriazene sulfonamides as carbonic anhydrase I, II, VII, and IX inhibitors. J Enzyme Inhib Med Chem. 2018;33(1):1575-80.

31. Blois MS. Antioxidant determinations by the use of a stable free radical. Nature. 1958; 181:1199-200.

32. Pellegrini RRN, Proteggente A, Pannala A, Yang M, Rice-Evans C. Antioxidant activity applying and improved ABTS radical cation decolorization assay. Free Rad Bio Med. 1999;26:1231-7.

33. Dinis TCP, Maderia VMC, Almedia LM. Action of phenolic derivatives (acetoaminophen, salycilate and 5aminosalycilate) as inhibitors of membrane lipid preoxidation and as preoxyl radical scavengers. Arc Biochem Biophy. 1994;315:161-9.

34. Apak R, Guclu K, Ozyurek M, Karademir SE. Novel total antioxidant capacity index for dietary polyphenols and vitamine C and $E$, using their cupric ion reducing capability in the presence of neocuproine: CUPRAC method. J Agric Food Chem. 2004;52:7970-81.

35. Ellman GL, Courtney KD, Andres V, Featherstone RM. A new and rapid colorimetric determination of acetylcholinesterase activity. Biochem Pharmacol. 1961;7:88-95. 
